\title{
Patterns of End-of-Life Oncologic Care for Stage IV Non-small Cell Lung Cancer in the United States
}

\author{
WAQAR HAQUE ${ }^{1}$, VIVEK VERMA ${ }^{2}$, E. BRIAN BUTLER ${ }^{1}$ and BIN S. TEH ${ }^{1}$ \\ ${ }^{1}$ Department of Radiation Oncology, Houston Methodist Hospital, Houston, TX, U.S.A.; \\ ${ }^{2}$ Department of Radiation Oncology, Allegheny General Hospital, Pittsburgh, PA, U.S.A.
}

\begin{abstract}
Background/Aim: Because aggressive oncological management just prior to death constitutes a substantial proportion of end-of-life (EOL) costs, we investigated patterns of EOL oncologic care for stage IV non-small cell lung cancer (NSCLC) in USA to better determine at which point in the patient's management new treatments were being initiated. Materials and Methods: The National Cancer Database was queried for stage IV NSCLC patients who received any cancer-directed therapy with known timing thereof. Results: A total of 281,990 stage IV NSCLC patients were analyzed. Of all patients, $10.8 \%$ commenced any firstcourse cancer therapy within four weeks of death, and $24.5 \%$ within eight weeks of death. Conclusion: 10-15\% of stage IV NSCLC patients start cancer therapy within four weeks of death, and 25-30\% within eight weeks. This represents a population for whom cancer therapy may not be required, which has implications on reducing EOL healthcare costs.
\end{abstract}

Costs of cancer care (roughly $\$ 173$ billion in the US by 2020) (1) are proportionally greatest in the last year of life; in that interval, they account for $>25 \%$ of the entire Medicare budget (over half of which is spent in the final 60 days) (2).

The most common cause of cancer-related death worldwide, non-small cell lung cancer (NSCLC) is most commonly diagnosed as stage IV disease and carries a very poor prognosis. Because aggressive oncologic management just prior to death constitutes a substantial proportion of endof-life (EOL) costs, we investigated patterns of EOL oncologic care for metastatic NSCLC in USA.

Correspondence to: Waqar Haque, MD, Department of Radiation Oncology, Houston Methodist Hospital, Cancer Center, and Research Institute, Weil Cornell Medical College, Houston, TX 77030, U.S.A. Tel: +1 8325228116, Fax: +1 7134414493, e-mail: waqarh786@gmail.com

Key Words: Non-small cell lung cancer, stage IV, end-of-life, healthcare costs, cost-effectiveness.

\section{Materials and Methods}

Details regarding the National Cancer Database (NCDB), which captures about $70 \%$ of the USA population, are provided elsewhere (3). The primary goal herein was to evaluate proportions of stage IV NSCLC patients initiating cancer therapy (radiation, chemotherapy, immunotherapy, or any therapy) within certain intervals of death. The NCDB does not give information on therapy cessation. Statistics included multivariable logistic regression to determine factors associated with death within 15 days of commencing cancer therapy.

\section{Results}

From 2004-2015, 1,393,073 NSCLC cases were recorded in the NCDB; 894,368 were stage I-III and 216,715 had no record/timing of death and/or therapy and were hence excluded. The overall population thus consisted of 281,990 stage IV NSCLC patients (Table I). There were several factors independently predictive of dying within 15 days of initiating cancer therapy: advancing age, male gender, higher comorbidities, Caucasian race, lower income, and advancing tumor/nodal disease $(p<0.05$ for all).

Figure 1A illustrates the distribution of patients starting any cancer therapy as a function of the time to death. Overall, $10.8 \%$ commenced first-course therapy within four weeks of death, and $24.5 \%$ within eight weeks of death. Just $23.2 \%$ of patients survived $>52$ weeks from the day of starting therapy.

Figure 1B-D provides a sub-breakdown regarding radiotherapy, chemotherapy, and immunotherapy, respectively. Within four and eight weeks of death, 13.9\% and $27.7 \%$ started a course of radiotherapy; corresponding figures for chemotherapy and immunotherapy were $10.9 \%$ \& $25.2 \%$ and $4.9 \%$ \& $11.5 \%$.

\section{Discussion}

Although stage IV NSCLC is being more aggressively managed (4), only a proportion of well-selected patients achieve oncologic benefit; rather, many patients starting cancer therapy die soon after the initiation of treatment. 


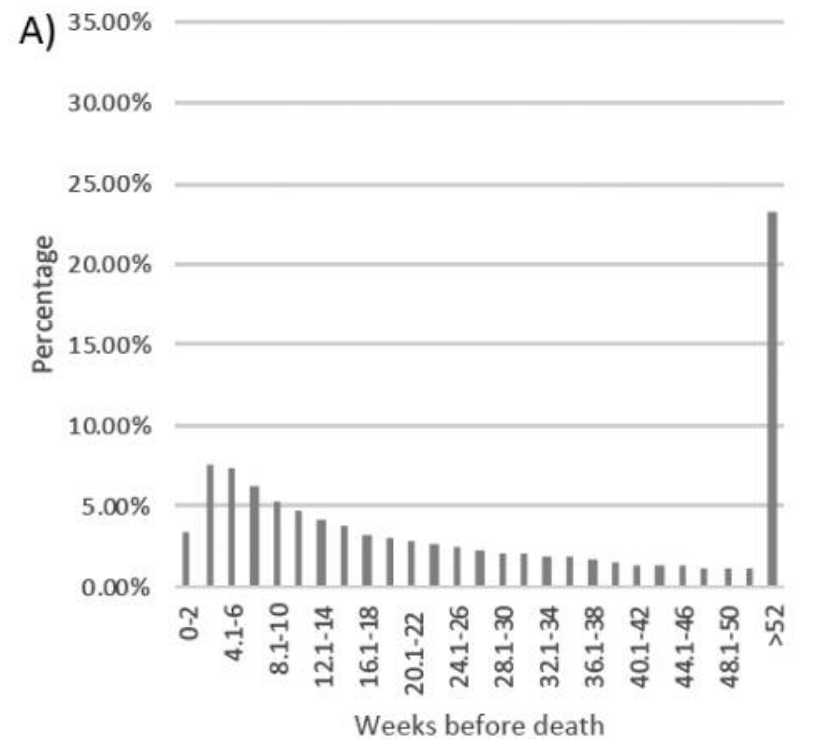

B)

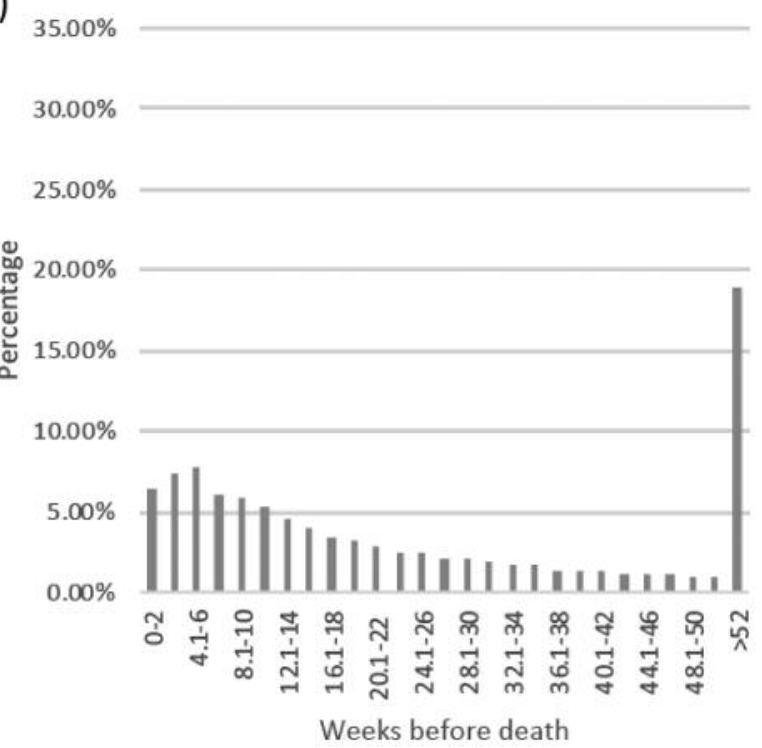

C) $35.00 \%$

D)

Weeks before death
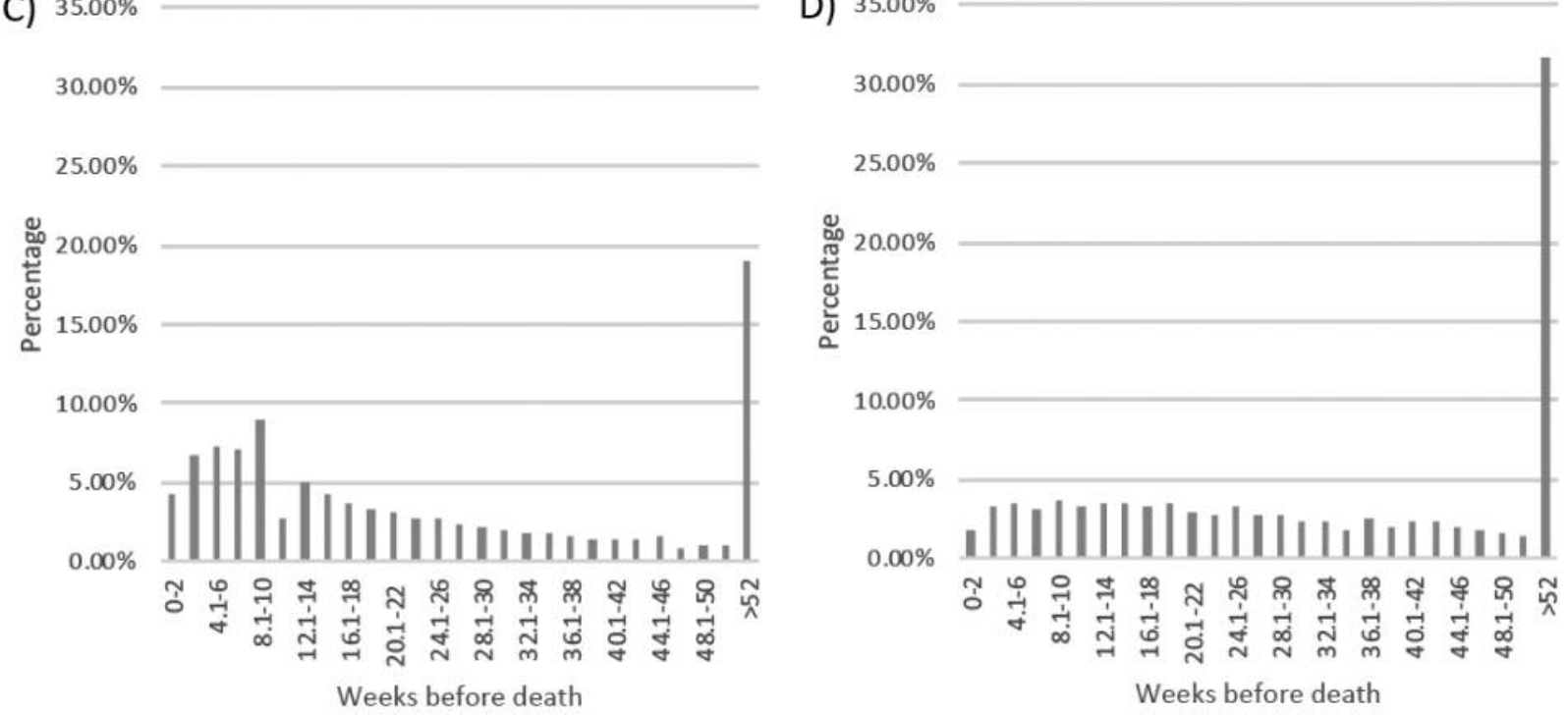

Figure 1. Proportion of patients receiving cancer therapy as a function of the time to death. A) Any cancer therapy, B) radiotherapy, C) chemotherapy, D) immunotherapy.

Oncological management is expensive, and because oncologic and EOL costs are rising worldwide, it is essential to perform audits regarding delivering "futile" cancer care just prior to death. This study of a large, contemporary national database shows that $10-15 \%$ of stage IV NSCLC patients start cancer therapy within four weeks of eventual death, and 25-30\% within eight weeks. This represents a population for whom cancer therapy may not be required, which has implications on reducing EOL healthcare costs.

Herein, it is not insinuated that EOL oncologic interventions do not help patients. For instance, palliative radiotherapy is effective to reduce symptomatic local tumor progression; in fact, studies have shown that effective palliative care actually reduces healthcare costs (5). We suggest that certain subpopulations herein received oncologic interventions as part of aggressive, unnecessary management towards the EOL. To this extent, several factors may be utilized by clinicians to carefully evaluate the risk of death a short time after intervention(s) are initiated (Table I).

The staggering rise of immunotherapy for metastatic NSCLC must also be contextualized with its immense costs (over $\$ 100,000$ for a single course). Because not all patients 
Table I. Clinical characteristics for all patients, and multivariable logistic regression analysis for factors associated with death within 15 days of starting cancer therapy.

\begin{tabular}{|c|c|c|c|c|}
\hline \multirow[b]{2}{*}{ Characteristic } & \multicolumn{4}{|c|}{ Multivariable logistic regression } \\
\hline & All patients $(n=281990)$ & Odds ratio & $95 \%$ Confidence interval & $p$-Value \\
\hline \multicolumn{5}{|l|}{ Age } \\
\hline$\leq 50$ & $25015(8.9 \%)$ & 1 (reference) & & \\
\hline $51-60$ & $63737(22.6 \%)$ & 1.233 & $1.176-1.292$ & $<0.001$ \\
\hline $61-70$ & $91239(32.4 \%)$ & 1.363 & $1.300-1.430$ & $<0.001$ \\
\hline $71-80$ & $76012(27.0 \%)$ & 1.559 & $1.483-2.640$ & $<0.001$ \\
\hline $81-90$ & $25987(9.2 \%)$ & 1.900 & $1.800-2.010$ & $<0.001$ \\
\hline \multicolumn{5}{|l|}{ Gender } \\
\hline Male & $158212(56.1 \%)$ & 1 (reference) & & \\
\hline Female & $123778(43.9 \%)$ & 0.820 & $0.803-0.837$ & $<0.001$ \\
\hline \multicolumn{5}{|l|}{ Race } \\
\hline White & $238787(84.7 \%)$ & 1 (reference) & & \\
\hline African American & $33405(11.9 \%)$ & 0.900 & $0.871-0.930$ & $<0.001$ \\
\hline Other & $9798(3.5 \%)$ & 0.882 & $0.831-0.935$ & $<0.001$ \\
\hline \multicolumn{5}{|l|}{ Insurance } \\
\hline Medicaid & $21539(7.6 \%)$ & 1 (reference) & & \\
\hline Medicare & $148878(52.8 \%)$ & 0.978 & $0.934-1.023$ & 0.333 \\
\hline Private & $89620(31.8 \%)$ & 0.847 & $0.811-0.884$ & $<0.001$ \\
\hline Uninsured & $12700(4.5 \%)$ & 1.319 & $1.244-1.400$ & $<0.001$ \\
\hline Other & $9253(3.3 \%)$ & 1.119 & $1.047-1.197$ & 0.001 \\
\hline \multicolumn{5}{|l|}{ Charlson/Deyo score } \\
\hline 0 & $183940(65.2 \%)$ & 1 (reference) & & \\
\hline 1 & $69580(24.7 \%)$ & 1.375 & $1.343-1.408$ & $<0.001$ \\
\hline 2 & $20921(7.4 \%)$ & 1.631 & $1.573-1.690$ & $<0.001$ \\
\hline$\geq 3$ & $7549(2.7 \%)$ & 1.895 & $1.794-2.002$ & $<0.001$ \\
\hline \multicolumn{5}{|l|}{ Income } \\
\hline$<\$ 46,000$ & $173766(61.6 \%)$ & 1 (reference) & & \\
\hline$\geq \$ 46,000$ & $97302(34.5 \%)$ & 0.947 & $0.927-0.969$ & $<0.001$ \\
\hline Not recorded & $10922(3.9 \%)$ & 1.016 & $0.963-1.071$ & 0.572 \\
\hline \multicolumn{5}{|l|}{ Facility } \\
\hline Academic & $86216(30.6 \%)$ & 1 (reference) & & \\
\hline Non academic & $193399(68.6 \%)$ & 1.055 & $1.031-1.079$ & $<0.001$ \\
\hline Not recorded & $2375(0.8 \%)$ & 0.880 & $0.763-1.015$ & 0.080 \\
\hline \multicolumn{5}{|l|}{ Histology } \\
\hline Adenocarcinoma & $138996(49.3 \%)$ & 1 (reference) & & \\
\hline Squamous cell carcinoma & $53118(18.8 \%)$ & 1.005 & $0.977-1.034$ & 0.727 \\
\hline Other & $89876(31.9 \%)$ & 1.169 & $1.142-1.197$ & $<0.001$ \\
\hline \multicolumn{5}{|l|}{$\mathrm{T}$ classification } \\
\hline $\mathrm{T} 1$ & $33159(11.8 \%)$ & 1 (reference) & & \\
\hline $\mathrm{T} 2$ & $70555(250 \%)$ & 1.274 & $1.223-1.328$ & $<0.001$ \\
\hline $\mathrm{T} 3$ & $38337(13.6 \%)$ & 1.534 & $1.467-1.604$ & $<0.001$ \\
\hline $\mathrm{T} 4$ & $87742(31.1 \%)$ & 1.786 & $1.717-1.858$ & $<0.001$ \\
\hline Not reported & $52197(18.5 \%)$ & 1.681 & $1.609-1.757$ & $<0.001$ \\
\hline \multicolumn{5}{|l|}{$\mathrm{N}$ classification } \\
\hline No & $49961(17.7 \%)$ & 1 (reference) & & \\
\hline N1 & $25278(9.0 \%)$ & 1.077 & $1.030-1.126$ & 0.001 \\
\hline $\mathrm{N} 2$ & $111007(39.4 \%)$ & 1.301 & $1.261-1.342$ & $<0.001$ \\
\hline N3 & $53342(18.9 \%)$ & 1.379 & $1.332-1.429$ & $<0.001$ \\
\hline Not reported & $42402(15.0 \%)$ & 1.324 & $1.273-1.378$ & $<0.001$ \\
\hline \multicolumn{5}{|l|}{ Year } \\
\hline 2004-2006 & $64953(23.0 \%)$ & 1 (reference) & & \\
\hline $2007-2009$ & $75260(26.7 \%)$ & 0.941 & $0.914-0.969$ & $<0.001$ \\
\hline $2010-2012$ & $87103(30.9 \%)$ & 0.937 & $0.910-0.965$ & $<0.001$ \\
\hline 2013-2014 & $54674(19.4 \%)$ & 1.092 & $1.058-1.128$ & $<0.001$ \\
\hline
\end{tabular}


will benefit, careful patient selection is critical to ensure that immunotherapy is delivered to well-selected patients with adequate life expectancy to reap its benefits (6). To this end, an important finding herein was that substantially lower proportions of patients started immunotherapy immediately before death, indicating some degree of more judicious screening for these expensive agents.

Limitations of the NCDB include the lack of treatment indications, costs, cancer-specific survival, number/volume of metastases, or type/duration of chemotherapy/ immunotherapy agents. This study was not designed to address the increasing number of stage IV NSCLC patients who experience long-term survival (4).

\section{Conflicts of Interest}

None. This study has never been presented/published before in any form. All Authors declare that conflicts of interest do not exist.

\section{Authors' Contributions}

$\mathrm{WH}, \mathrm{VV}, \mathrm{EBB}$, and BST contributed to the conception of the project and drafting the manuscript.

\section{Funding}

There was no research support for this study.

\section{References}

1 Mariotto AB, Yabroff KR, Shao Y, Feuer EJ and Brown ML: Projections of the cost of cancer care in the United States: 20102020. J Natl Cancer Inst 103: 117-128, 2011. PMID: 21228314. DOI: $10.1093 /$ jnci/djq495
2 Lubitz JD and Riley GF: Trends in Medicare payments in the last year of life. N Engl J Med 328: 1092-1096, 1993. PMID: 8455667. DOI: $10.1056 /$ NEJM199304153281506

3 Bilimoria KY, Stewart AK, Winchester DP and Ko CY: The National Cancer Data Base: A Powerful Initiative to Improve Cancer Care in the United States. Ann Surg Oncol 15: 683-690, 2008. PMID: 18183467. DOI: 10.1245/s10434-007-9747-3

4 Gomez DR, Blumenschein GR Jr., Lee JJ, Hernandez M, Ye R, Camidge DR, Doebele RC, Skoulidis F, Gaspar LE, Gibbons DL, Karam JA, Kavanagh BD, Tang C, Komaki R, Louie AV, Palma DA, Tsao AS, Sepesi B, William WN, Zhang J, Shi Q, Wang XS, Swisher SG and Heymach JV: L Local consolidative therapy versus maintenance therapy or observation for patients with oligometastatic non-small-cell lung cancer without progression after first-line systemic therapy: A multicentre, randomised, controlled, phase 2 study. Lancet Oncol 17: 16721682, 2016. PMID: 27789196. DOI: 10.1016/S1470-2045(16) 30532-0

5 Dalal S and Bruera E: End-of-life care matters: Palliative Cancer Care Results in Better Care and Lower Costs. Oncologist 22: 361-368, 2017. PMID: 28314840. DOI: 10.1634/theoncologist. 2016-0277

6 Verma V: Economic sustainability of immune-checkpoint inhibitors: the looming threat. Nat Rev Clin Oncol 15: 721-722, 2018. PMID: 30127492. DOI: 10.1038/s41571-018-0086-z. 